\title{
Los atlas históricos de ciudades: instrumentos para la interpretación de los procesos urbanos. Santa Fe (Argentina), 1880-1945
}

1. Esta visión reductiva de la iconografía urbana como mera ilustración es denunciada por Francisco Da Costa (2009). Explica también Da Costa que al trabajar los atlas de ciudades: “...no deberíamos perder de vista las aproximaciones de carácter verificador y comparativo para vincular el dato documental con el objeto de la disciplina -la ciudad y su tiempo-y como herramienta para comprender los procesos urbanos locales como parte de un proceso más amplio de la realidad urbana (regional, territorial y global)" (Da Costa, 2009).

\author{
Adriana Collado \\ María Luisa Bertuzzi \\ María Elena Del Barco*
}

Las imágenes de ciudad han funcionado, así, como lentes a través de los cuales

observar la historia de la cultura y de las ideas.

Lucia Nuti, Ritratti di città.

Cuando Giorgio Piccinato explicó que la historia de la urbanística y la historia de las ciudades pueden seguir itinerarios convergentes o divergentes, que no se trata de historias paralelas, sino de recorridos que se tocan en algunos momentos y se alejan en otros (Piccinato, 1977, p. 5), dejó planteada una clara diferencia entre historia de la urbanística (en tanto historia disciplinar) e historia de las ciudades (en tanto biografías de los objetos-ciudad). A partir de esa diferencia, el campo de la historia urbana puede ser entendido como el de un saber que vincula las transformaciones de las ciudades con el contexto disciplinar general, un saber que se encarga de interpretar las alternancias en los recorridos y que permite dilucidar en qué fenómenos se origina esa falta de coincidencia, posibilitando abordar la contingencia, en sus encuentros y desencuentros con los paradigmas de la historia disciplinar.

La presente investigación ubicada en el campo de la historia urbana, pretendió con el Atlas Histórico, producir un instrumento multifacético partiendo de reconocer el valor del discurso del documento gráfico, que es mucho más que la simple descripción de una realidad urbana determinada, mucho más que una mera ilustración ${ }^{1}$. Así, lo que se buscaba era por una parte, sistematizar información disponible sobre una ciudad determinada a fin de que los datos documentales pudieran ser puestos en relación; por otra, posibilitar a partir de dicho documento gráfico, el análisis comparativo de los distintos fenómenos que convergen en esa situación urbana seleccionada; y finalmente, generar una herramienta que al desvelar los discursos ocultos en cada testimonio, permita interpretar y comprender los procesos urbanos en confrontación con los paradigmas del saber disciplinar vigentes en cada momento.

El objeto de estudio fue la ciudad de Santa Fe, que es capital de la provincia argentina del mismo nombre, situada $450 \mathrm{~km}$ al noroeste de Buenos Aires, a orillas de un afluente del río Paraná, con una población de 415.000 habitantes (Censo Nacional, 2010). Fundada en 1573 por el vizcaíno Juan de Garay, esta fue trasladada entre 1650 y 1660 a su actual emplazamiento $80 \mathrm{~km}$ al sur del primero, reproduciendo con exactitud en la nueva ubicación, la disposición originaria de su trazado cuadricular,

* Cómo citar este artículo: Collado, A., Bertuzzi, M.L., Del Barco, M.E. (2013). Los atlas históricos de ciudades: instrumentos para la interpretación de los procesos urbanos. Santa Fe (Argentina), 188-1945. En Apuntes 26 (1): 170 - 185. 



\section{Los atlas históricos de ciudades: instrumentos para la interpretación de los procesos urbanos. Santa Fe (Argentina), 1880-1945}

The Historical Atlas of Cities: Instruments for the Interpretation of Urban Processes. Santa Fe (Argentina), 1880-1945

0 atlas histórico das cidades: instrumentos para a interpretação dos processos urbanos. Santa Fe (Argentina), 1880-1945

Adriana Collado

acollado48@hotmail.com

Arquitecta de la Universidad Católica de Santa Fe, Argentina (1981); Doctora de la Universidad Pablo de Olavide de Sevilla, España (2008). Profesora e investigadora de la Facultad de Arquitectura, Diseño y Urbanismo de la Universidad Nacional del Litoral desde 1985. Docente de posgrado en cuatro universidades nacionales de Argentina. Ha dictado seminarios de posgrado, cursos y conferencias en México, Brasil, Chile, Francia y España.

María Laura Bertuzzi

mlba_@hotmail.com

Arquitecta de la Universidad Nacional del Litoral, Santa Fe, Argentina. Magíster y candidata a doctora de la Universidad Politécnica de Cataluña, España. Profesora adjunta regular en materias de pregrado de Urbanismo e Historia y en carreras de posgrado en la FADU-UNL.

María Elena Del Barco

maeledbi@yahoo.com.ar

Arquitecta de la Universidad Nacional del Litoral, Santa Fe, Argentina. Candidata a Magíster de la Universidad Nacional de Tucumán. Docente de grado del área de Ciencias Sociales en la FADU-UNL.

Universidad Nacional del Litoral, Argentina.

Resumen

Este artículo pretende resumir los fundamentos teóricos y los postulados metodológicos que sustentaron la construcción de un Atlas Histórico urbano de una ciudad provinciana del Litoral argentino, Santa Fe. Partiendo de un nutrido y diverso fondo documental, producto de una prolongada tarea de investigación, el atlas fue concebido como un instrumento que permitió sistematizar, representar e interpretar distintas etapas en la conformación de la ciudad durante el transcurso del proceso de modernización (1880-1945). Sobre los documentos cartográficos se operó la lectura crítica y la posterior preparación de una nueva cartografía, restituyendo la secuencia de crecimiento urbano en sucesivos cortes temporales para disponer de una base cartográfica homogénea y producir el mapeo de los distintos indicadores del nivel de urbanización de la ciudad para cada momento histórico.

Palabras claves: Patrimonio documental, historia urbana, representaciones

Descriptores: Arquitectura-Historia-Atlas, desarrollo urbano- Santa Fe (Argentina), fondos documentales

Abstract

This article aims to summarize the theoretical and methodological grounds of the construction of an urban historical atlas of Santa Fe, a capital city of a province in Argentina. The Atlas is based in a large and diverse collection of documents which is the product of a long research work. It has been designed as a tool that allows systematizing, representing and interpreting different stages in the formation of the city during its modernization process (18801945). The paper offers a critical reading on the cartographic documents in order to draw a new set of maps to depict the urban growth sequence throughout successive cuts in the time line. It also has the intention of constructing a homogeneous cartographic database and mapping the various indicators of the level of development of the city for each historical moment.

Keywords: Documentary heritage, urban history, representations

Keywords plus: Architecture-History-Atlas, urban-Santa Fe (Argentina), documentary collections

investigación llevada a cabo en la Facultad de

Arquitectura, Diseño y Urbanismo de la

Universidad Nacional del Litoral de Santa Fe, Argentina, subsidiado por la Secretaría de Ciencia y

Técnica de la universidad y que se titula "Atlas Histórico de Santa Fe (1880-1945)”.

Recepción: 1 de febrero de 2013.

Aceptación: 5 de junio de 2013.

\section{Resumo}

O presente artigo resume os pressupostos teóricos e metodológicos que apoiaram a construção de um atlas histórico urbano de uma cidade do estado de Santa Fé na Argentina. A partir de uma grande e diversa coleção de documentos e produto de um longo trabalho de pesquisa, o atlas foi concebido como uma ferramenta que permite sistematizar, representar e interpretar diferentes estágios na formação da cidade durante o processo de modernização (18801945). Uma leitura crítica e posterior elaboração de novos mapas foram feitos com base nos documentos cartográficos, restaurando a seqüência do crescimento urbano em pontos sucessivos de tempo, para ter dados cartográficos homogêneos e produzir assim os mapas dos diferentes indicadores do nível de desenvolvimento da cidade para cada tempo histórico.

Palavras-chave: Patrimônio documental, história urbana, representações

Palavras-chave descritores: Arquitetura-História-Atlas, urbano-Santa Fe (Argentina), acervos documentais doi:10.11144/Javeriana.APC26-1.ahci

* Los descriptores y keywords plus están normalizados por la Biblioteca General de la Pontificia Universidad Javeriana. 
la localización de sus principales edificios y la estructura de propiedad de la tierra.

En el período colonial Santa Fe estuvo signada por carencias propias de su deficiente localización, afrontando periódicas crecientes de los ríos, sufriendo ataques de grupos indígenas, padeciendo un relativo aislamiento geográfico. Esto obstaculizó su crecimiento económico y edilicio. A mediados del siglo XIX Santa Fe era una población pequeña con una imagen urbana homogénea, chata, sin mayores alternativas.

En cambio, los últimos años del siglo XIX e inicios del XX se caracterizaron por la transformación del rol que tuvo Santa Fe en su espacio de influencia, con importantes modificaciones económico-productivas en su territorio circundante; esto produjo cambios notables en la ciudad misma, con fuerte crecimiento poblacional y transformaciones étnicas y culturales basadas en una alta afluencia de inmigrantes europeos. El proceso estuvo marcado también por la irrupción de las infraestructuras de transporte (ferrocarriles, puerto, puentes, caminos) que impulsaron el proceso modernizador y produjeron transformaciones sustanciales en la escena urbana y en la configuración de la ciudad. El Atlas Histórico que presentamos aquí se enfoca precisamente en el marco cronológico (1880-1945) de este proceso de fuerte transformación de la ciudad heredada del período colonial y analiza los cambios que esta incorporó al insertarse en las nuevas estructuras económicas y materiales del país.

\section{El Atlas Histórico como patrimonio}

Abordar los objetos cartográficos en su dimensión patrimonial lleva a considerar la sutil correspondencia del patrimonio cultural con la cuestión de la memoria y en especial, de la memoria colectiva, que establece nexos entre las tres dimensiones temporales (pasado, presente y futuro) y encuentra en las ciudades un lugar de convergencia de recuerdos, afectos e ideales comunes. La cartografía histórica, en tanto retrato de ciudad, adquiere una significación central para el abordaje desde la perspectiva de la memoria: en tanto documento figurativo comunica información sobre un estado pretérito del objeto; pero a la vez, según sea el enfoque adoptado por el cartógrafo, según las capacidades técnicas puestas en juego, el dominio científico que demuestra, los

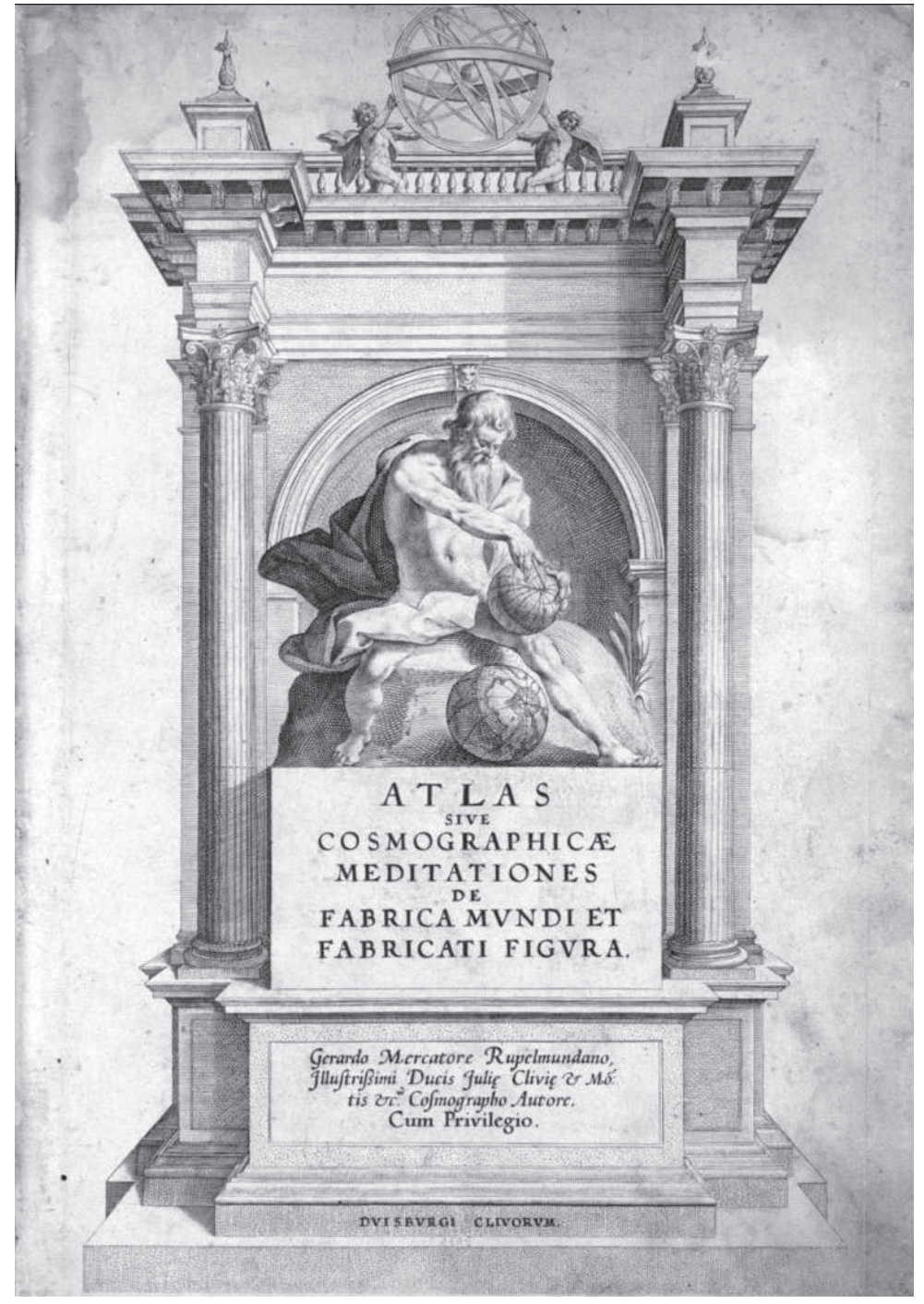

códigos figurativos y el sistema de convenciones aplicados, permitirá una lectura mucho más comprehensiva de la época que produjo dicho documento y por tanto, de la situación coyuntural de la ciudad en estudio (Nuti, 1996).

$\mathrm{Al}$ bucear en el origen del vocablo memoria, surge la asociación con la figura de Mnemosyne, una titánide de la mitología griega considerada la diosa de la memoria. Hija de Urano (el firmamento) y de Gea (la tierra), Mnemosyne no solo disponía de la potestad de conocer el pasado sino que unida a Zeus, había engendrado a las nueve musas inspiradoras de las artes. Así, el pensamiento occidental le reconoce a la memoria un valor que trasciende la mera instrumentalidad de dominio del conocimiento en el tiempo y le asigna una dimensión productivocreativa. Esa dimensión creativa estaría puesta en juego cuando se entiende al documento cartográfico en términos de patrimonio cultural,
Figura 1

Portada del Atlas, Sive Cosmographicae Meditationes De Fabrica Mundi et fabricati figura de Gerardus Mercator, editado en 1595.

Fuente

http://kat.ph/atlassive-cosmographicaefabrica-mundi-etfabricati-figuragerardus-mercatordui-t2897772.html meditationes-de- 
Figura 2

Plano de la ciudad de

Santa Fe que acompaña

la edición del Primer

Censo General de la

Provincia en el año

1887. Este plano

resume, sobre la planta

urbana, los datos del

censo de población

que fue dirigido por el

Dr. Gabriel Carrasco.

Fuente:

GOBIERNO DE LA

PROVINCIA DE SANTA

FE. (1888). Primer

Censo General de la

Provincia - 1887.

Buenos Aires: Peuser.

2. Un caso paradigmático de atlas iconográfico y una verdadera cartografía de la memoria puede hallarse en la experiencia de Aby Warburg y su magnífico proyecto intelectual, el Atlas Mnemosyne, desarrollado entre 1924 y 1929 . Se trata de una colección de mágenes estratégicamente seleccionadas y articuladas discursivamente, mediante la cual, prescindiendo de texto literario, Warburg pretendía narrar la historia de la memoria (y del arte) de la civilización europea (Warburg, 2010).

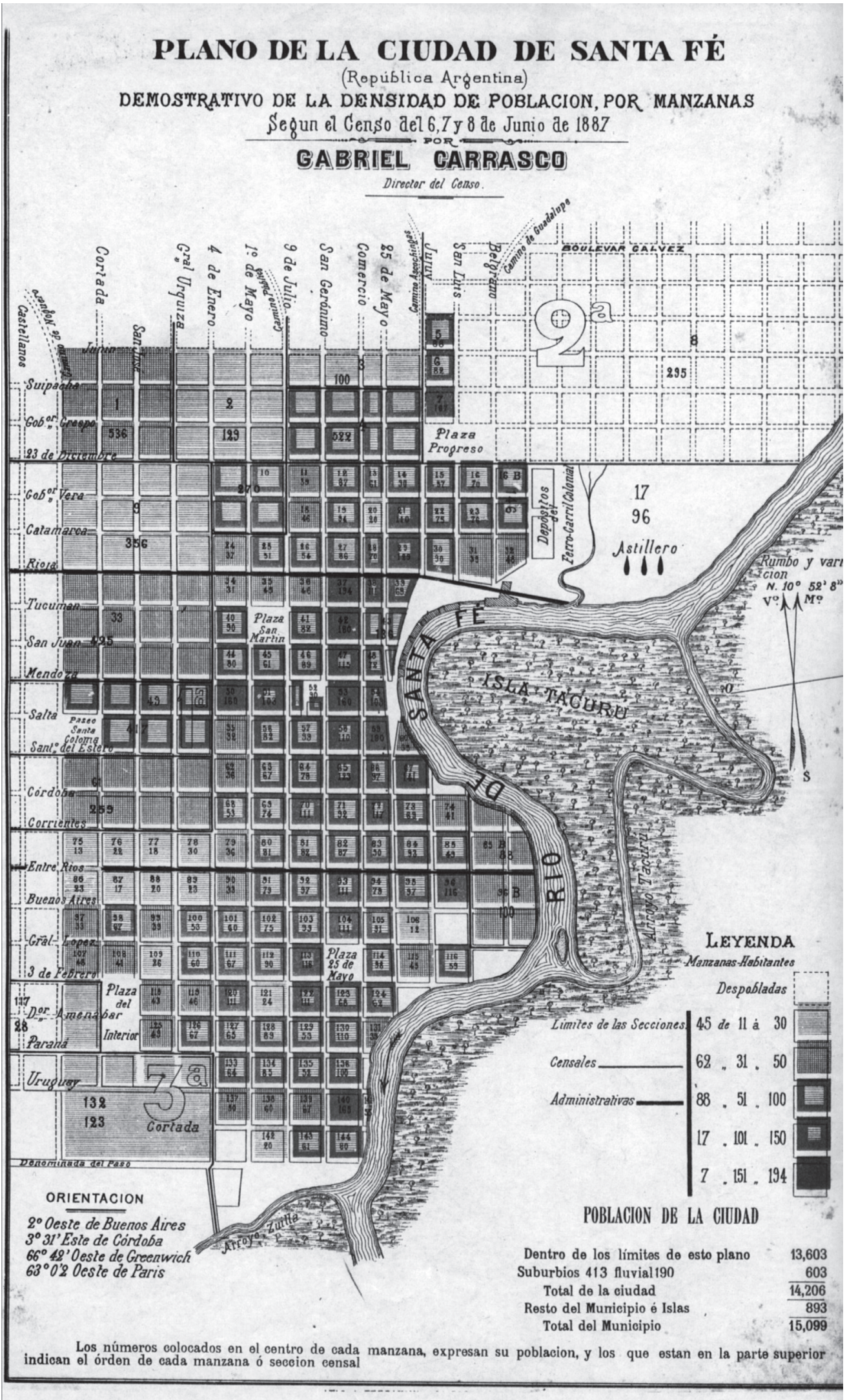

como creación, como productor de sentido y no como mero descriptor de una realidad que le es externa ${ }^{2}$.
Vinculada con la noción de memoria, la cartografía queda ubicada en el complejo nivel de la obra de invención, donde juega también 
el plano de las valoraciones y de los afectos: el documento no es algo que nos recrea una información neutra, aséptica sobre un objeto; por el contrario, en la construcción del documento cartográfico se recorta intencionadamente el objeto y la perspectiva desde la que se lo quiere memorizar. En el marco de la visión de lo cartográfico como patrimonio, podrían definirse a los planos urbanos como un tipo especial de testimonios materiales que reconocen el paso del tiempo, tienen noción de historicidad y en tanto consagraciones a la memoria, incluyen en sí mismos algo de permanente (Choay, 2007, p. 12$)^{3}$.

Por otra parte, el término atlas deriva de la mitología griega, en cuyo contexto Atlas o Atlante es una suerte de titán al que el dios Zeus había castigado con la tarea de cargar sobre sus hombros los pilares que mantenían la tierra separada de los cielos. En griego antiguo, atlas

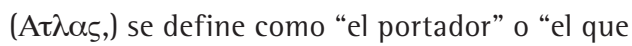
soporta” y deriva del verbo $\tau \lambda \alpha \dot{\omega} \omega$ que significa “portar" o “soportar" (Pabón de Urbina, 2005, p. 93 y p. 586). Como nombre propio, Atlas se relaciona también con la figura de un mítico rey de Mauritania, sabio, filósofo, matemático y notable astrólogo, descubridor de la esfericidad de las estrellas y creador del primer globo celeste. Por todo esto se le representa como un personaje fantástico que lleva el firmamento completo sobre sus hombros.

Cuando se publicó Atlas, Sive Cosmographicae Meditationes De Fabrica Mundi et fabricati figura del geógrafo flamenco Gerardus Mercator (1512-1594) en 1595, se homenajeó la figura del rey de Mauritania incluyendo una representación suya en la portada y usando por primera vez el término Atlas para describir un libro de mapas. Se cerraba así un siglo en el que este tipo de recopilaciones habían comenzado a adquirir notoriedad en tanto constituian la evidencia del dominio europeo sobre el mundo. A partir de Mercator se generalizó el uso del término, a la vez que se difundió considerablemente la edición de colecciones cartográficas (mapas territoriales y luego planos de ciudades) cada vez más sistemáticas; hijas dilectas de la modernidad, por su capacidad de dar cuenta del dominio del hombre sobre el mundo, mostrando los avances en el conocimiento y la capacidad de representación del mismo.

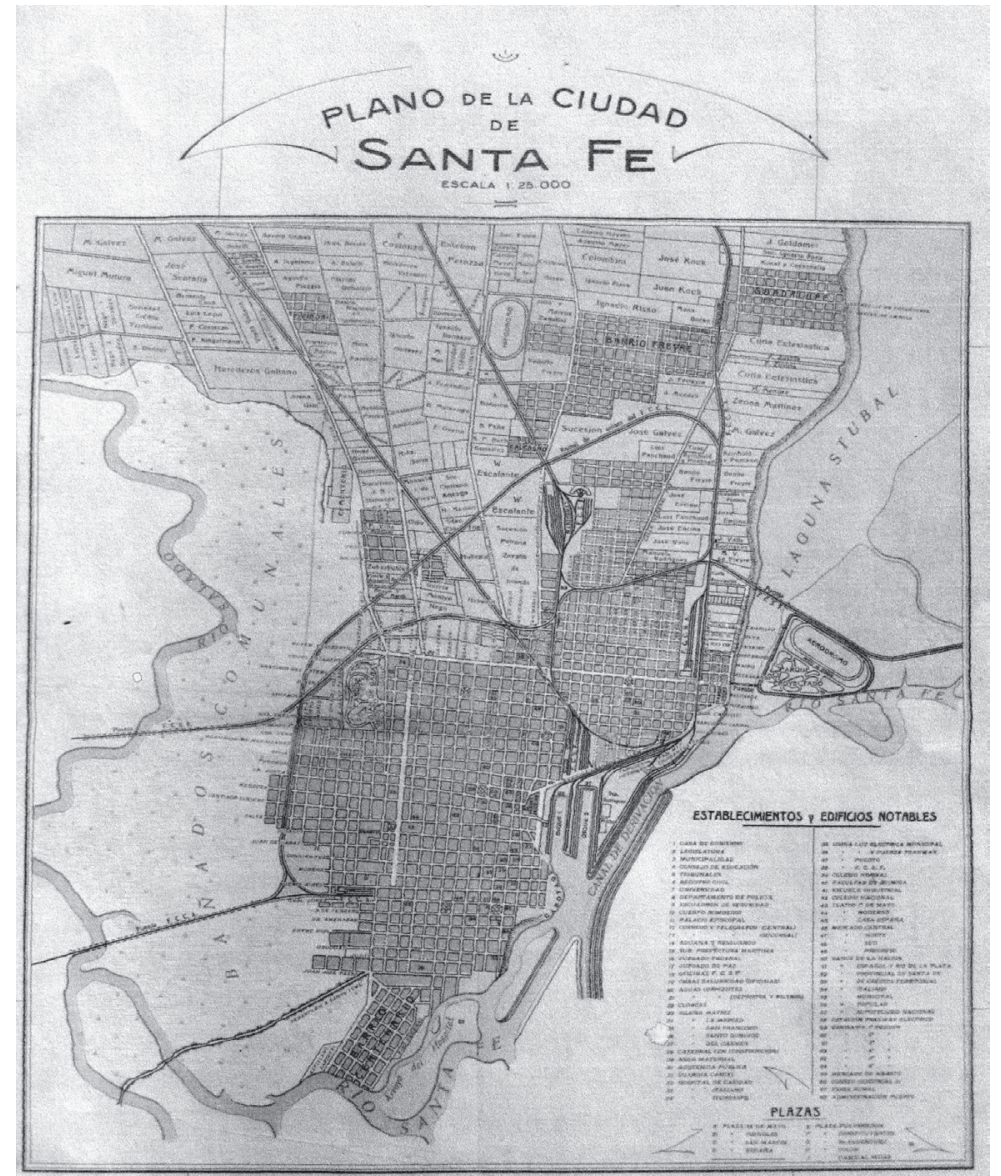

Los documentos cartográficos

$\mathrm{Al}$ asumir como preocupación central de este trabajo el hecho de que el Atlas Histórico opere como un instrumento para el conocimiento, el análisis y la interpretación de los procesos urbanos, vale la pena volver sobre la etimología de origen, es decir, atlas como sinónimo de "el que soporta"; en este sentido se otorga a los documentos la condición de soportes de la información y los testimonios disponibles sobre la ciudad. Un atlas moderno, es importante aclararlo, no solo compila cartografía de diferentes ciudades y diferentes momentos, sino que se nutre de otras fuentes iconográficas, estadísticas y literarias diversas, con lo que robustece su condición de soporte privilegiado de los saberes y de la información que da sentido a la pretensión cognitiva.

Cabe también traer a colación la noción de representación de Roger Chartier desde la que se orientó la investigación: todo texto es una representación de la realidad, una construcción retórica que tratará de aprehender dicha realidad según diferentes modalidades; no existen textos que tengan una relación ingenua o transparente
Figura 3

Plano de la ciudad de Santa Fe editado por la Dirección Provincial de Obras Públicas y Geodesia, 1924. Este plano es un detalle de un plano mayor, de gran formato, de toda la provincia, presentado en colores y en escala 1:200.000, dibujado en planos parciales y luego montado en un plano general.

Fuente:

ADPC, Archivo de la Dirección Provincial de Catastro de Santa Fe.

3. En este conocido trabajo de F. Choay, la autora abunda en referencias acerca de la noción de memoria, testimonio y monumento. 
Figura 4

Plano general de trazado del Bulevar Gálvez y del Barrio Candioti, atribuido al ing. Emilio Schnoor, presentado ante el Municipio en octubre de 1887 y aprobado en 1889.

Fuente:

Archivo de la Dirección Municipal de Catastro de Santa Fe, Carpeta: Planos varios, "Plano Directorio de la Parte Nord-Este de la Ciudad de Santa Fe".

4. Un trabajo ejemplar en esta perspectiva es aque sobre la cartografía de Buenos Aires realizado por la investigadora del Instituto

de Arte Americano de la UBA, Graciela Favelukes, para su tesis doctoral. Algunos de sus presupuestos pueden verse en Favelukes (2011, pp. 11-26).

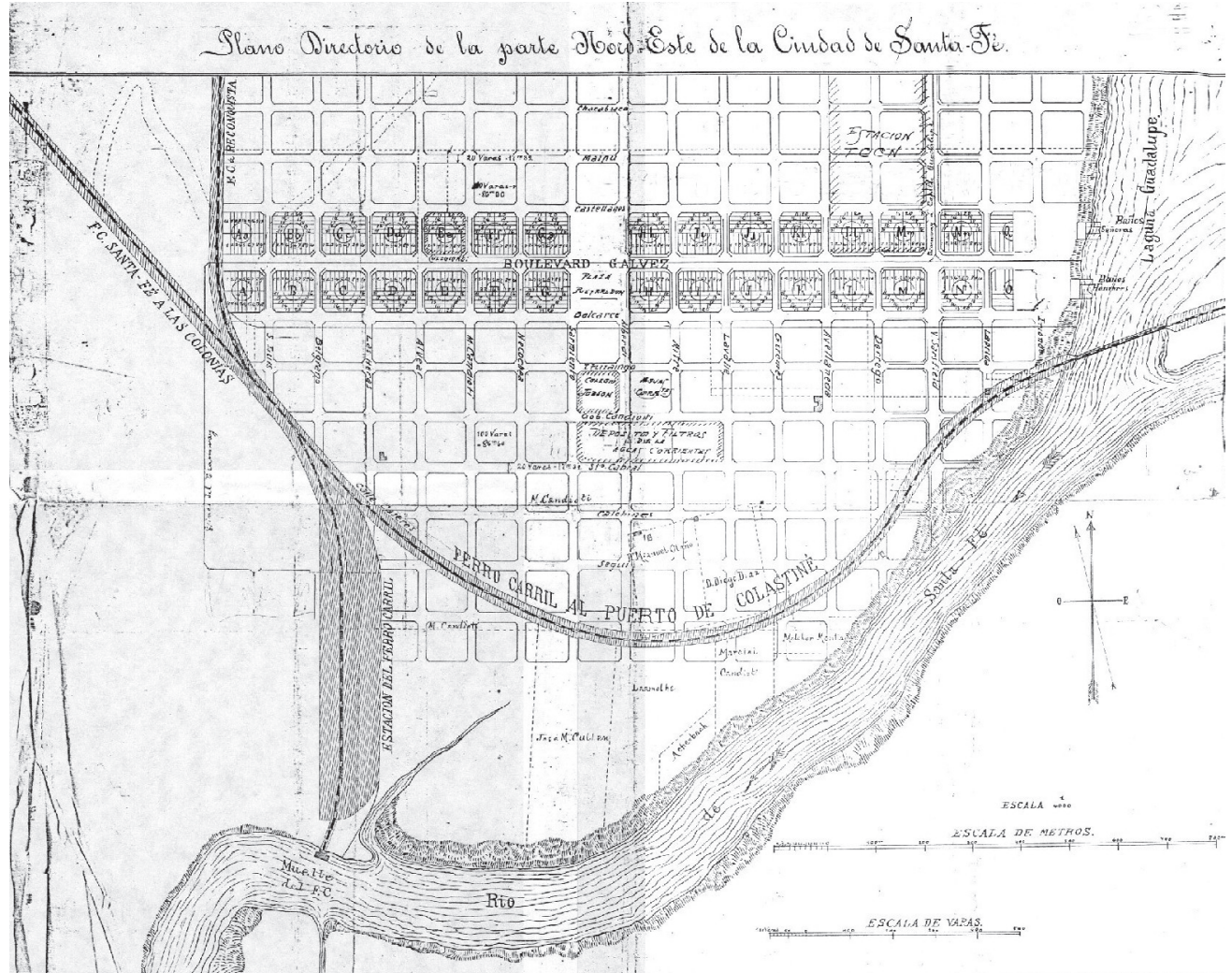

con la realidad, esa relación dependerá siempre, de una estrategia discursiva (Chartier, 1992, pp. 39-40). La representación, en el caso de la cartografía urbana, pasa a ser parte de la forma de la ciudad al restituir el tiempo vivido a través del signo gráfico. Según Paolo Sica, toda elaboración gráfica que intente captar el fenómeno urbano plenamente, es capaz también de expresar la dinámica de sus relaciones (Sica, 1981).

El presente trabajo, además de reconocer el valor central de representación de la cartografía, se interesó en ver cómo funciona su operación práctica a manera de instrumento que, a través de una lectura crítica, permite verificar los modos en los que el saber disciplinar intervino sobre la ciudad, influyendo en las formas de ordenar los espacios, perfilar la normativa y las políticas urbanas, formalizar los ámbitos jerárquicos y equilibrar los sistemas de equipamientos y servicios ${ }^{4}$. Es así como la cartografía pudo actuar como un mecanismo de valor operativo en la aproximación a la historia urbana que relaciona los procesos de construcción que la modernidad perfiló para las distintas ciudades del mundo occidental.

Los planos históricos ocupan, sin dudas, un lugar preponderante entre las fuentes a las que debe recurrir el historiador urbano, dado que permiten visualizar la realidad espacial, física y geográfica del fenómeno en estudio, pero también aportan a la comprensión de las mentalidades que sustentan esa realidad. Producidos en las claves propias de sus momentos de origen, los mapas de ciudades brindan, mediante una lectura atenta que maneje esas claves, la posibilidad de que no se desperdicie el cúmulo de información implícita que contienen.

Con recursos menos evidentes que los de la pintura o la fotografía, en el sentido de una correspondencia iconológica entre imagen y objeto representado, la cartografía urbana posee un valor análogo en cuanto a sus posibilidades de representar, no solo los estados de hecho sino también los cambios. Se puede considerar que la cartografía urbana es y fue siempre, una construcción que estuvo históricamente situada en la puja entre exigencias técnico-documentales, que le reclaman que la representación sea idéntica a la realidad representada y exigencias estéticosimbólicas, que cargan de significación cultural al objeto representado y a la representación en sí misma. Por esto la producción cartográfica se asimila al fenómeno que surge desde mediados del siglo XIX: la fotografía urbana. André Corboz (1995) explica este contrapunto como la permanente oscilación a la que se somete la construcción del documento cartográfico entre el polo 
verista y el polo fantástico; de allí emerge la idea de que es imperioso no entender el mapa o plano como restitución objetiva de la realidad.

En toda la cartografía urbana renacentista es evidente la fundamental operación de mediación entre la construcción científica y el programa ideológico-propositivo, manipulando la imagen urbana con el objetivo de que las ciudades sean vistas en su conjunto, como unidad y organizada jerárquicamente en torno a la emergencia de ciertos hitos claves y significativos ${ }^{5}$.

Otro momento y transformación dentro del campo de la cartografía urbana que puede considerarse clave en esta evaluación, se da en el siglo XVIII cuando se generaliza la producción de plantas de ciudades en planos geométricos o cenitales y se asume una utilización práctica de la representación, directamente orientada a posibilitar las operaciones de intervención y control del espacio urbano globalmente, lo que se contrapone a los planos en perspectiva que tendían a un uso simbólico de la representación. Este cambio coincide con un proceso de objetivación del espacio urbano que se manifiesta desde mediados del XVIII, momento en el que la ciudad comienza a convertirse en tema de estudio y análisis científico. En este sentido, el paso de la imagen-espectáculo a la imagen abstracta de la planta cenital va en consonancia con el cambio en el campo disciplinar.

Son apenas dos momentos en la historia urbana de las ciudades occidentales que permiten, en definitiva, reafirmar la idea de que estudiar el objeto ciudad en sus dimensiones, en sus escalas relativas y en la relación con el territorio, tomar conciencia del impacto de las transformaciones urbanísticas, mapear información sobre el funcionamiento de infraestructuras y servicios sobre evolución demográfica, lleva siempre a una cierta representación de la ciudad. Aún así, no puede olvidarse que (...)

la cartografía urbana no es nunca inocente, ni aún en sus manifestaciones aparentemente más objetivas y neutrales. Toda cartografía es siempre una operación de construcción en el sentido más fuerte del término (Guardia, Monclús y Oyón, 1997, p. 128).

Cabe agregar un hecho a todas las valoraciones ya señaladas que, en mayor o menor medida, es generalizable a la mayoría de ejemplos de cartografía urbana investigada: su valor como instrumentos del proyecto, en tanto exceden el nivel descriptivo de los fenómenos para convertirse en herramienta para la ideación de nuevos emprendimientos o, cuanto menos, de demostración sobre cómo se pensaba y se esperaba que la ciudad fuese en el futuro. En este sentido, el documento gráfico tanto reproduce como re-propone la ciudad, brindando una imagen sistemática que pone en relación lo real y lo deseado.

\section{Cartografía, ciudad y territorio}

Como se señalaba anteriormente, los planos históricos tienen un importante valor documental y ofician como puentes entre el pasado y el presente al permitir entender los procesos urbanoterritoriales de un espacio determinado, de una ciudad y su entorno o de una región. Estas grafías contienen datos relativos a la ciudad del pasado -en tanto construcción o urbs- y datos relativos a los elementos naturales en la propia ciudad, incluyendo referencias a lo natural y lo antropizado del territorio inmediato que la ciudad contribuye a conformar y que a su vez, se ve conformado por el mapa o plano en cuestión. En la presencia de los elementos naturales representados (ríos, arroyos, bosques, elevaciones, depresiones, entre otros); del mismo modo, los elementos naturales no representados, el desconocimiento voluntario o involuntario del territorio. Otro tanto puede decirse de los elementos antrópicos, resultado de la acción de la mano del hombre sobre el paisaje; los caminos, los puentes, los equipamientos periféricos, la presencia de los poblados cercanos representados en las cartografías explican cómo la ciudad se vincula con su entorno y al igual que en la afirmación anterior, su ausencia significa que estas relaciones se desconocen o bien no interesan para la cartografía concreta que está siendo construida.

A la vez, como se decía más arriba, si bien algunas de las representaciones son estrictamente realistas, en su mayoría contienen una dosis de fantasía o incluso de proyección idealizada que a veces se filtra sin que el dibujante lo haga de manera explícita como dato fehaciente de la realidad. Esto conduce en algunas ocasiones a equívocos y en otras, a intencionalidades subyacentes, indicios de una ciudad anhelada que deben ser develados por la historia urbana.
5. Un ejemplo sobre la Florencia renacentista es la conocida Pianta della Catena (1472) que no se vale de una proyección fantástica sino de la topografía para realizar la configuración planimétrica y aplica la perspectiva como medio de control de la observación. No obstante, un estudio geométrico comparativo entre lo que el documento propone y lo que hubiese resultado de una aplicación objetiva de los principios de perspectiva manejados entonces, permite verificar grandes discrepancias con respecto al grado de compactación del perfil urbano que fueron provocadas deliberadamente para lograr ciertos efectos escenográficos con relación al poder de los Medici en el espacio urbano. (Fanelli, 1985). 
Figura 5

Imagen de la plaza

fundacional de la

ciudad a fines del siglo

XIX, cuando había ido

perdiendo los rasgos

del espacio colonial

$y$ adquiriendo una

nueva fisonomía, a la

europea, con algunos

árboles exóticos, bancos

$y$ farolas; 1895.

Fuente:

Banco Digital de

Imágenes Florián Paucke.

Archivo General de la

Provincia de Santa Fe, código: 101203383.

7. Su origen es la Oficina Topográfica Militar creada en 1879 durante la presidencia de Nicolás Avellaneda y como consecuencia de la Expedición al Desierto. En el mismo año se creó su biblio teca, que hoy en día funciona como centro de consulta en el predio del Instituto Geográfico Nacional (IGN) en la Ciudad Autónoma de Buenos Aires. El IGN, históricamente conocido como Instituto Geográfico Militar (IGM) tomó dicha denominación en mayo de 2009.

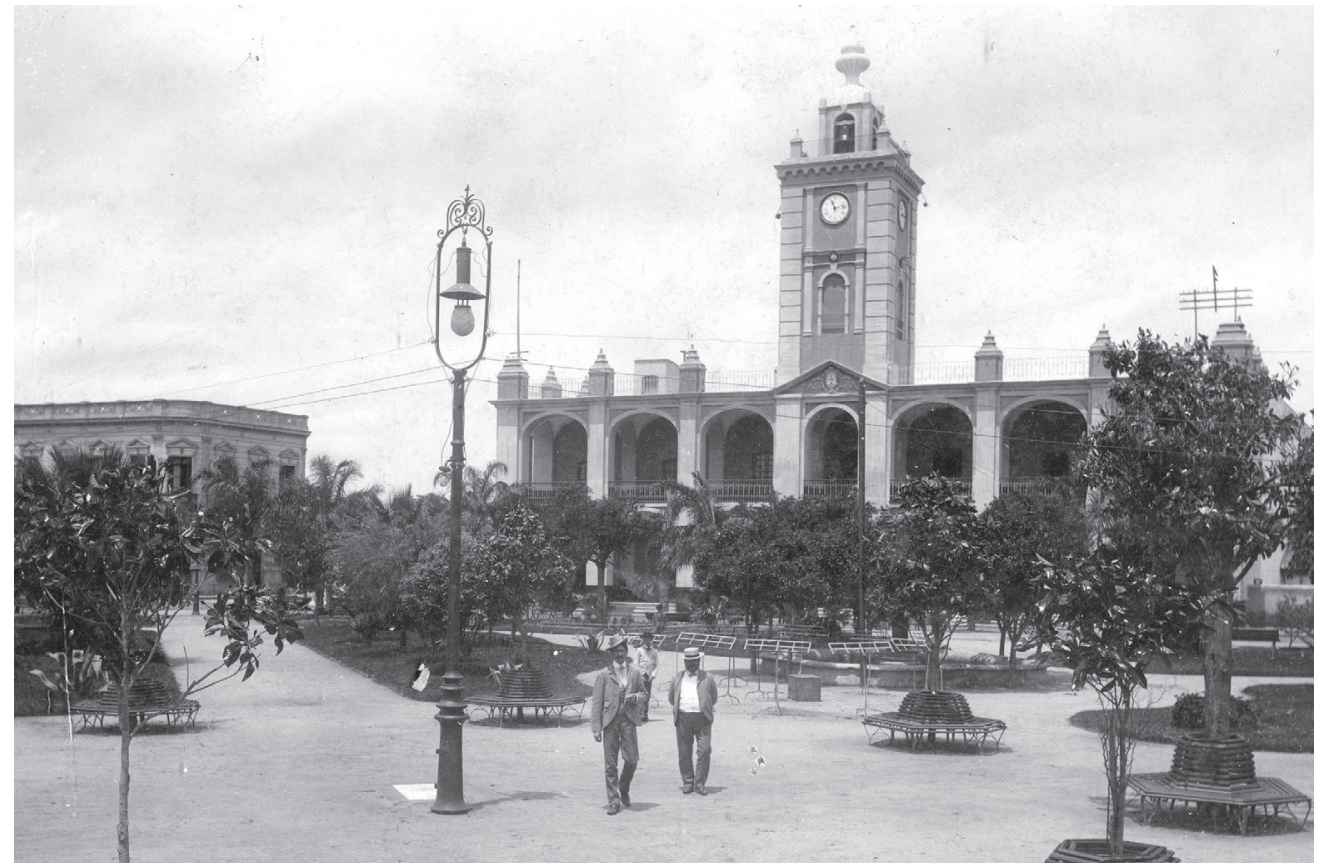

En relación a las fuentes y los archivos de donde provienen, los planos históricos han sido construidos por distintos actores y por distintos entes, que lo hacen en función de sus propios intereses (cuestión que se desarrolla más adelante). Además y en parte por esa misma causa, estos se encuentran dispersos en distintos archivos, algunos públicos (de distintos niveles del Estado) y otros privados, algunos accesibles y otros restringidos. Por lo tanto la posibilidad de compilarlos y editarlos en un atlas constituye un acto de publicidad de los mismos que permite divulgar la información que contienen pero, por sobre todo, logra que los procesos que explican y representan se hagan accesibles -especialmente a la comunidad académica-, contribuyendo así a fortalecer la cultura en general y, específicamente, las cultura urbana y de planificación. Su publicación conlleva un acto de necesaria interpretación que contribuye a su mejor comprensión, pero el propio acto de hacerlos públicos los expone a una pluralidad de interpretaciones puesto que se multiplica la población que puede acceder a los mismos.

Las diferentes escalas de representación son también un dato importante dado que desde áreas urbanas específicas hasta territorios enteros, reales y concretos, son sometidos a un proceso de abstracción que convierte a esa complejidad tridimensional en un documento que sintetiza y transmite su estado en un momento histórico específico. Así pueden encontrarse desde cartas geográficas de valor estratégico, construidas en base a técnicas de fotointerpretación, hasta planos de agrimensura que tienen obviamente, objetivos y preocupaciones muy diversas entre ellos, pasando por cuidadosas representaciones de áreas urbanas en las que se dibujan incluso los edificios que conforman el tejido urbano.

Cada escala de representación debe resolver el problema de qué y cómo se representa, pregunta reiterada por siglos, que si bien ha sido respondida con la construcción de códigos gráficos convencionales, no implica homogeneidad y debe ser develada en la lectura de cada plano. A medida que se avanza desde la escala urbana hacia la territorial, los procesos de síntesis y abstracción aumentan y se produce una mayor pérdida de información, justificada en la necesidad de hacer comprensible el objeto representado.

\section{La cartografía en el Atlas santafesino}

Lo dicho en estos últimos párrafos se verifica en la cartografía específica que fue utilizada en la construcción del Atlas Histórico de la ciudad de Santa Fe que, lejos de ser homogénea, resulta de muy diversas fuentes y representa una multiplicidad de intereses. La mayoría de los planos empleados para este trabajo fueron construidos por los departamentos técnicos municipales, pero también se han usado frecuentemente aquellos elaborados por el departamento topográfico provincial. Estos últimos 


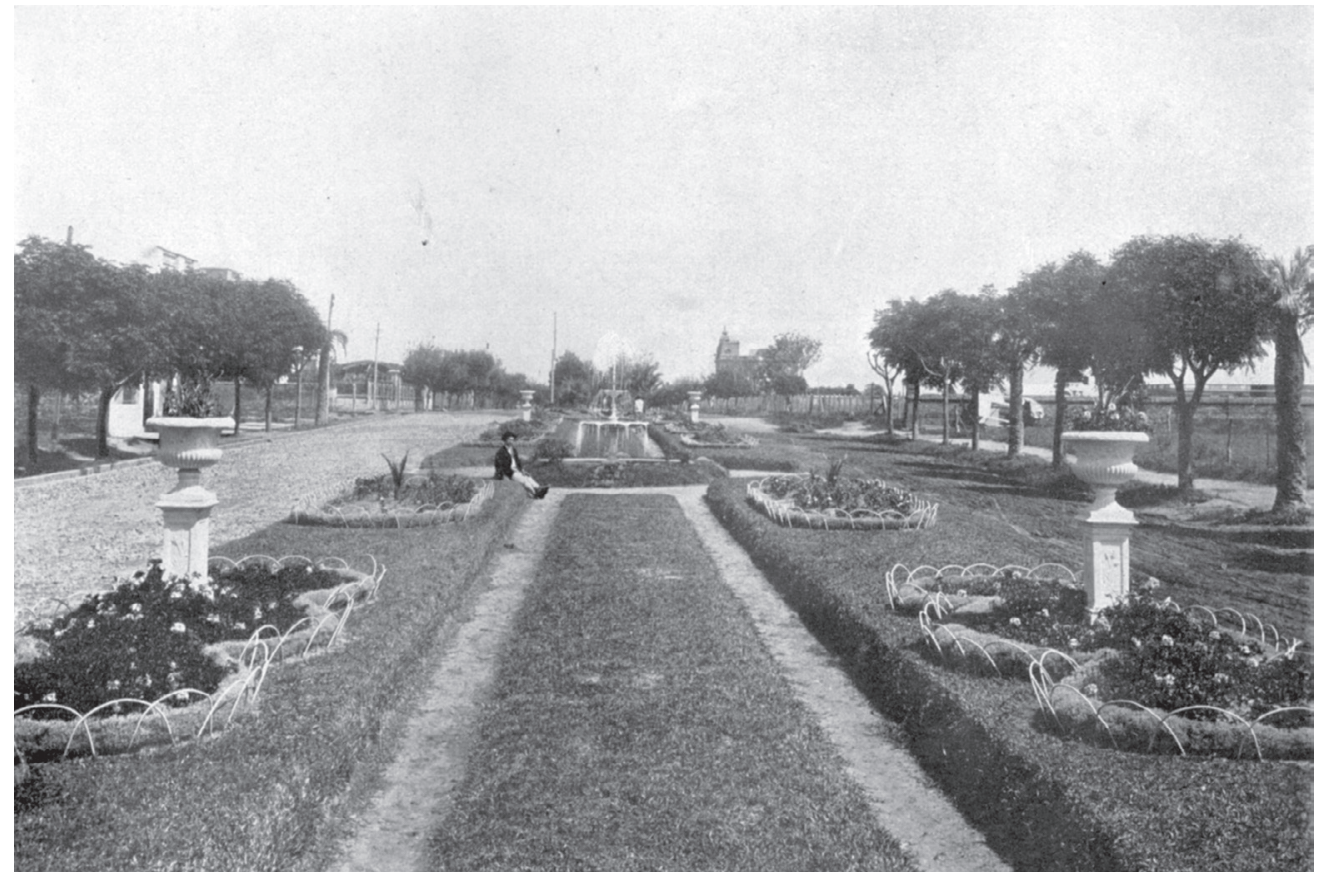

presentan como principal aporte, la posibilidad de relacionar la ciudad con el territorio provincial y también con las ciudades más importantes de la provincia de Santa Fe, dado que solían ser dibujados en forma simultánea, con los mismos códigos de representación y escala, facilitando así su comparación casi inmediata.

Para este trabajo también se han utilizado planos censales, comerciales, o de entes públicos, tales como los de Obras Sanitarias de la Nación y planos de origen militar, como los del Instituto Geográfico Militar (IGM) ${ }^{7}$. Párrafos aparte merecen los dos últimos: la Dirección de Obras Sanitarias de la Nación, por su carácter de dependencia nacional, archivó durante muchos años en sus oficinas locales, no solamente planos urbanos en los que se representaba analíticamente la red de distribución del agua potable y la red de cloacas, sino además planos privados domiciliarios en donde se representaba la planta arquitectónica de cada vivienda a la que se proveía de alguno de estos servicios, constituyendo así un archivo extraordinario para la historia de la ciudad.

Por su parte, el IGM, hoy en día Instituto Geográfico Nacional (IGN), realizó relevamientos aerofotográficos y planimétricos de todo el país, con mayor grado de detalle en algunas áreas urbanas. Este trabajo, que se llevó a cabo de manera sistemática, con una misma metodología y códigos de representación unificados, es también una extraordinaria fuente para conocer los procesos urbanos y territoriales de la ciudad y es -junto con el histórico Departamento Topográfico de la Provincia de Santa $\mathrm{Fe}^{8}$ - el que mayor homogeneidad presenta entre todos los registros utilizados.

Con escasas excepciones el manejo de estos documentos ha sido descuidado, anárquico y muchas veces incluso malicioso, perdiéndose muchos documentos de gran valor, especialmente en la década neoliberal de 1990. En la actualidad todavía no se han desarrollado políticas de preservación y accesibilidad a los mismos y persiste un alto riesgo sobre su integridad.

La cartografía santafesina, a diferencia de otras, es sobria y austera; son planos simples que no contienen casi representación de edificios que den cuenta del paisaje urbano, ni de equipamientos y artefactos que representen los procesos de modernización. Extendida de manera exasperante, aparece la cuadrícula urbana como persistencia inamovible en el desarrollo de la ciudad. No se presentan sino excepcionalmente, cambios de módulo de la misma, ni giros en su direccionalidad.

A escala territorial lo inamovible es el catastro, que plasma los límites de las parcelas extraurbanas como si fueran límites de gran contundencia física y no líneas de propiedad, las que persisten durante años hasta ser transformados con las operaciones de urbanización. Persiste también la orientación en las parcelas extra-urbanas, resultado del mantenimiento de unas pocas reglas simples y hasta el momento no develadas completamente
Figura 6

Vista del bulevar trazado al noreste de la planta urbana en 1887 donde puede observarse la condición de ciudad de nueva planta y la baja densidad de ocupación, transcurrido un cuarto de siglo desde el origen del mismo, 1912.

Fuente:

Municipalidad de la Ciudad de Santa Fe. Anuario Estadístico de la ciudad de Santa Fe 1908-1909, Ed. Ramón lbáñez, 1910.

8. El Departamento Topográfico de la Provincia de Santa Fe fue fundado en $1862 \mathrm{y}$ efectivizado en 1863 por el gobernador Patricio Cullen, con la Oficina de Topografía y Estadística, cuyas funciones incluían la delineación de los pueblos y la construcción de sus planos. Hoy esas funciones son realizadas por el Servicio de Catastro e Información Territorial en la ciudad de Santa Fe. EI SECIT cuenta con cartografía histórica de toda la provincia.

9. La referencia corresponde a una cita de Juan José Saer, en la que sintetiza la condición de la pampa en una muy poética pero precisa frase de Roger Caillois: "Le doy gracias a esta tierra que exagera tanto la parte del cielo" (Saer, 1991). 


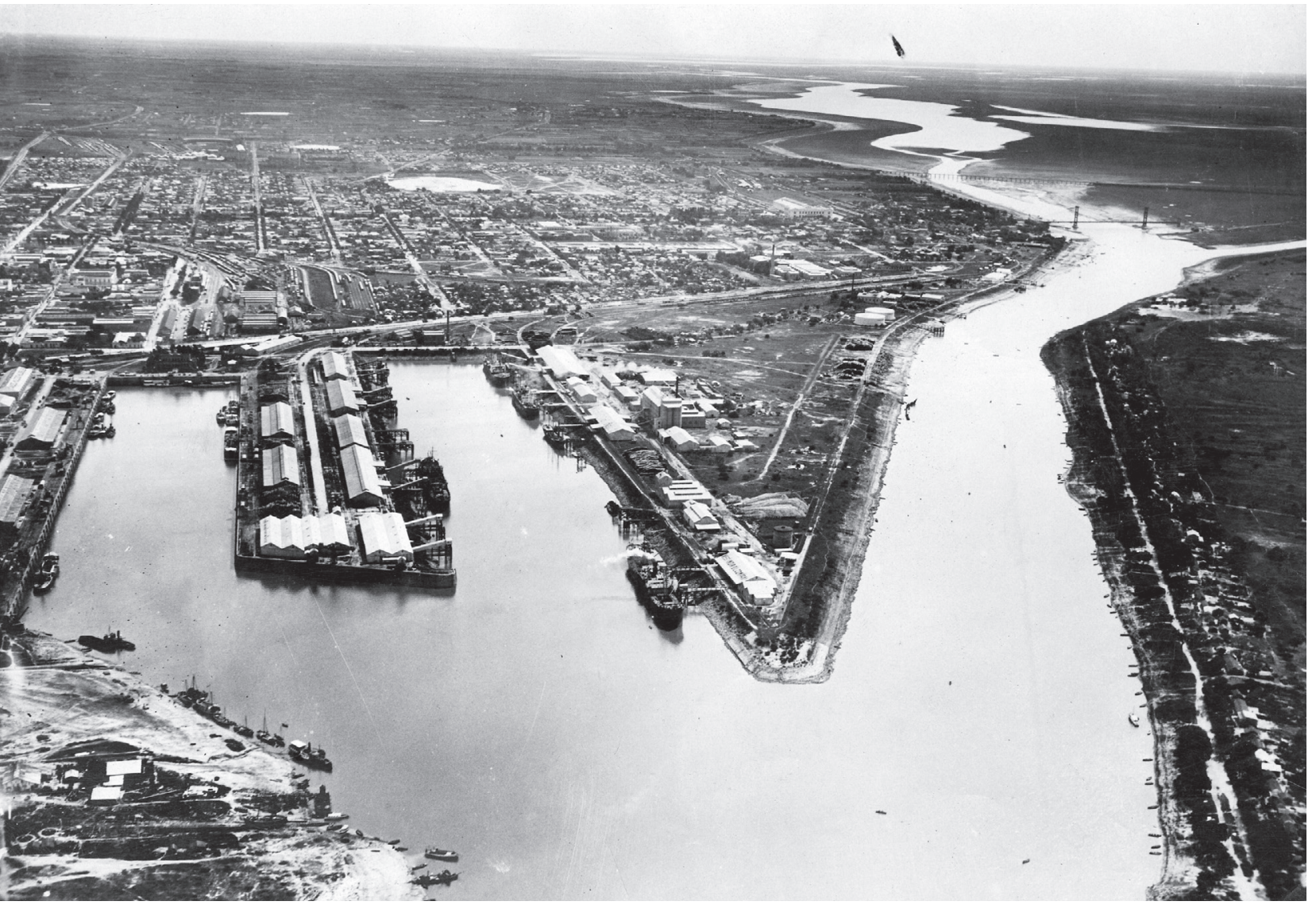

Figura 7

Vista aérea de la zona norte de la ciudad de Santa Fe hacia 1930. En primer plano, el Nuevo Puerto de Ultramar inaugurado en 1911; hacia la derecha, el albardón de Alto Verde, barrio de obreros portuarios $y$, al fondo, el puente acueducto $y$ el puente ferroviario.

Fuente:

Archivo General de

la Nación, código: AGN-195292. por la historiografía local. De igual manera, en las escalas urbana y metropolitana las trazas ferroviarias llenan de cicatrices un territorio plano, que “exagera la parte del cielo" (Saer, 1991) ${ }^{9}$.

Un dato inquietante que puede descubrirse en la mirada atenta de la cartografía santafesina son los cursos de agua que surcan el territorio urbano y los cuerpos lagunares. Estos caracterizan a un paisaje ribereño e isleño que constituye un continuo desafío técnico para bordes urbanos, trazas y puentes que una y otra vez deben ser mejorados e incluso reconstruidos ante el cambio de los cursos de ríos y arroyos y el embate de las frecuentes crecientes de los ríos Paraná y Salado con sus inundaciones ordinarias y extraordinarias. La cartografía de Santa Fe, desde muy temprano, asume ese reto de representación dibujando incluso en ocasiones, la variación de los caudales de los ríos, la aparición de islas e islotes y a veces las fracciones de tierras ganadas al agua.

\section{La fotografía histórica en el Atlas}

Para articular el atlas urbano resultó necesario amalgamar, además de la cartografía, una serie de fuentes de distinta procedencia que se tornaron imprescindibles para conseguir una lectura que abarcara diferentes frentes. Entre dichas fuentes se encuentran la fotografía histórica, las postales urbanas, la pintura, la prensa, los relatos de viajeros, la literatura de ficción, los registros estadísticos, la literatura técnica, etc., que aportaron a la integración del atlas. Por razones de espacio nos detendremos en especial en la primera de ellas, ya que el trabajo con la fotografía histórica se constituyó en un apoyo y un complemento esencial de la cartografía, de gran significación para avanzar en la reconstrucción del proceso de configuración urbana.

La fotografía, uno de los grandes acontecimientos del siglo XIX, constituyó en su origen el nuevo vehículo expresivo que permitió representar con fidelidad la imagen urbana. A partir de la segunda mitad del siglo XIX mostró desde los escenarios más solemnes hasta los aspectos más triviales de lo cotidiano, captando a la vez la vitalidad y la dinámica de los espacios, con una enorme capacidad de transmitir los significados que estaban más allá de lo propiamente material.

En este trabajo, al igual que en el caso de los documentos cartográficos, se intentó un acercamiento a las fotografías despojándolas de 


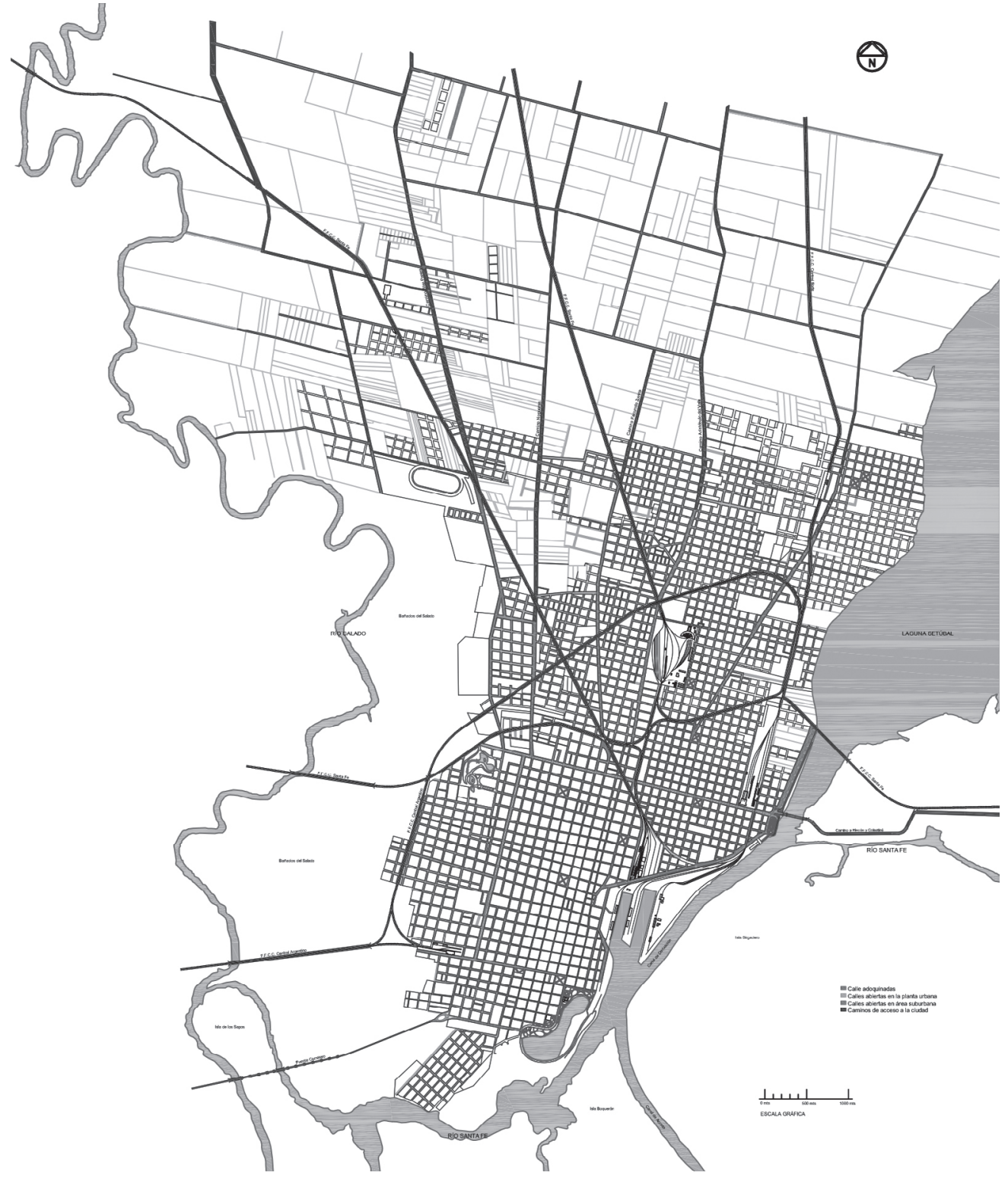

toda ilusión de realidad. Siguiendo los postulados de Susan Sontag, se entiende que fotografiar "significa establecer con el mundo una relación determinada que parece conocimiento $\mathrm{y}$, por lo tanto, poder" (2006, p. 16). De ahí que las imágenes fotográficas sean entendidas como visión intencionada de una situación determinada, como recorte de la realidad, aún cuando la particularidad de las imágenes fotográficas sea parecer "miniaturas de realidad que cualquiera puede hacer o adquirir” (Sontag, 2006, p. 17).

La amplia gama de registros, que incluyó desde fotografías históricas hasta tarjetas postales, desde piezas de colecciones de estudios fotográficos hasta parte de publicaciones periódicas, de ediciones oficiales de gobierno a publicaciones sobre conmemoraciones especiales, permitió acceder a distintos relatos sobre la ciudad, con énfasis y ocultamientos intencionados.

Las publicaciones municipales, como anuarios estadísticos y memorias de gobierno, retratan la obra pública y particularmente los espacios verdes públicos en las dos primeras décadas del siglo XX como indicadores de modernidad. Entre las ediciones conmemorativas, la editada a nivel provincial con motivo del Centenario de la Independencia argentina en 1916 permite contrastar los avances de la ciudad de Santa Fe con aquellos dados en la provincia, deteniéndose especialmente en retratar la actividad privada de instituciones comerciales y empresas, sin descartar por ello a la obra pública en sus distintas escalas.

Para superar esa condición de la fotografía que la supone un espejo de la realidad, se seleccio-
Figura 8

Reconstrucciones de indicadores de urbanización. Trazado y situación de la RED VIAL en 1945.

Fuente:

Plano de elaboración propia. Dibujo V. Borgarello. 
Figura 9

Reconstrucciones de planes. Plan de Urbanización de 1927. Es el primer plan urbanístico desarrollado para Santa $\mathrm{Fe}$, en el estricto sentido de la definición; una iniciativa presentada al Concejo Deliberante por el concejal Julio Cabal en diciembre de 1927, que fue aprobado sobre tablas inmediatamente, dictándose una ordenanza al efecto. Fuente:

Plano de elaboración propia. Dibujo V. Borgarello.

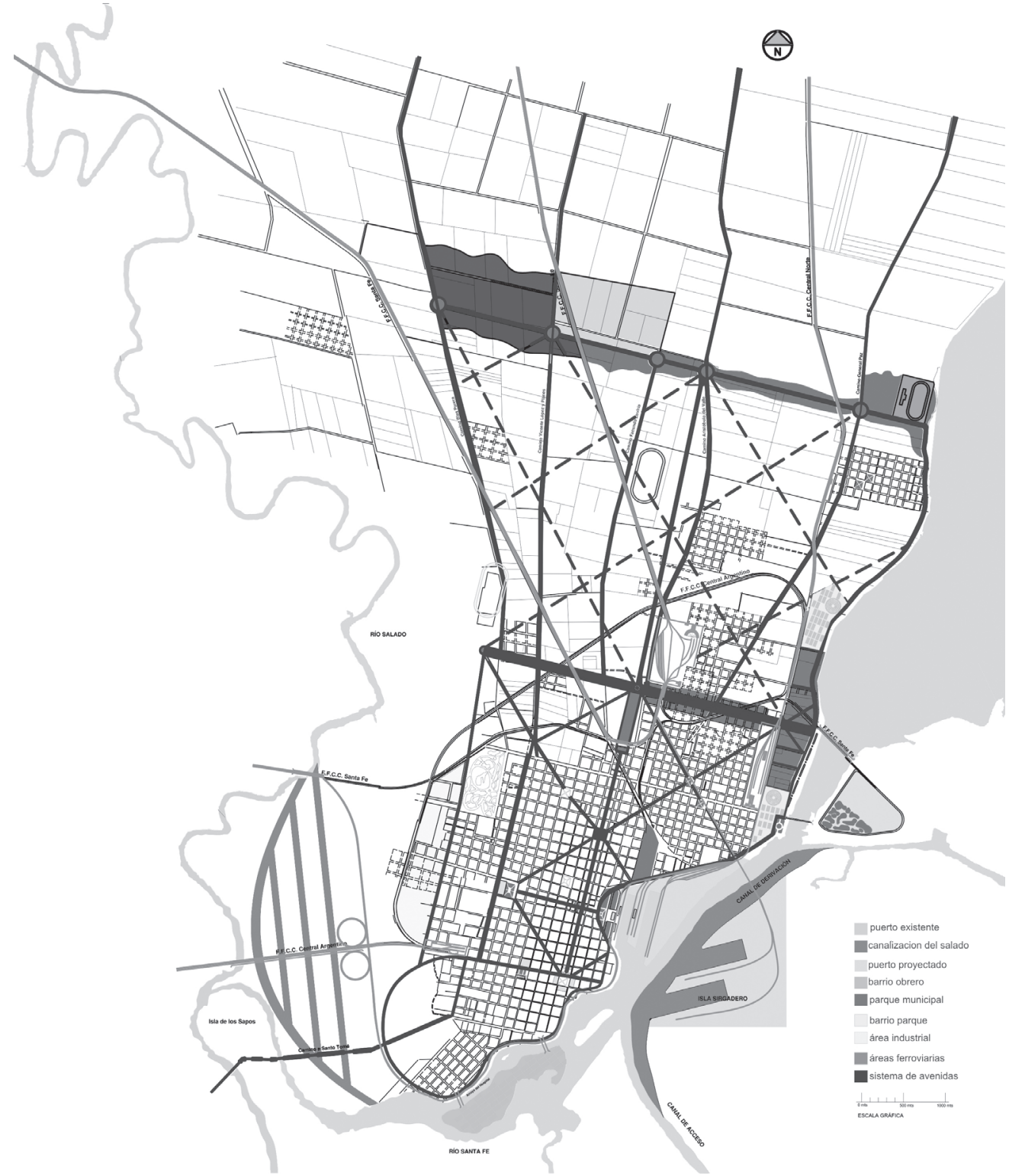

naron tanto vistas normales y de ámbitos significativos, así como vistas panorámicas. En la década de 1880 dos fotógrafos muestran distintas caras de la ciudad, aun siendo contemporáneas: José María de Iriondo retrata la plaza fundacional con una perspectiva centrada en el cabildo, poniendo énfasis en los ámbitos más institucionalizados; en tanto que Ernesto Schlie se detiene en los edificios industriales y comerciales en un reportaje fotográfico producido para ser exhibido en la Exposición Universal de París de 1889.

Los nuevos espacios públicos concentran la atención cuando aparecen como ámbitos de representación social, tal es el caso del Bulevar Gálvez, cuyo retrato se reitera, en la primera década del siglo XX, en tarjetas postales y publicaciones oficiales. Las vistas panorámicas, desde las pri- meras conocidas en la década de 1880 , registran el crecimiento urbano y la densidad edilicia sin ofrecer tantos detalles. De este modo, el ojo del observador es el que construye una mirada, un "modo de ver", tal como lo denomina John Berger, condicionado decisivamente por quienes realizan los encargos de las fotografías.

Para la construcción del atlas, la selección de imágenes fue realizada con la intención de registrar el proceso de modernización urbana en Santa Fe a partir de los indicadores de urbanización propuestos, con lo cual se fueron dejando de lado materiales que apuntaban a otros aspectos, como la persistencia o continuidad de espacios. Por ejemplo, del ámbito de la plaza fundacional, del que se disponen registros en casi todos los períodos, interesa sobre todo en los momentos 
en los que se renueva y aún así mantiene su dominancia como centro físico y social.

En la búsqueda de documentos se relevaron en primera instancia, los materiales disponibles en repositorios locales, como museos, bibliotecas y archivos, de acceso relativamente fácil pero muy dispersos en su localización. En los últimos años, la sistematización en un Banco digital de imágenes del Archivo General de la Provincia de Santa Fe facilitó el acceso al material, si bien el armado de buscadores poco flexibles limitaron la potencialidad del recurso. A nivel nacional, se realizaron búsquedas en el Departamento de Documentos Fotográficos del Archivo General de la Nación, donde se accedió a valiosas imágenes no disponibles en el medio local que se refieren generalmente a infraestructuras de gestión nacional como puertos y ferrocarriles.

El estudio de las imágenes fotográficas hizo posibles distintas lecturas sobre la realidad urbana, algunas más científicas y pretendidamente objetivas, pero sobre todo, dio lugar a la comprensión de una variedad de aspectos ligados a la significación social y a la interpretación de la dinámica urbana.

\section{Las reconstrucciones cartográficas}

En la construcción del Atlas Histórico de Santa Fe se aplicó una metodología relativamente poco usual en los atlas cartográficos que consiste en el redibujo de los planos urbanos. No debe entenderse con esto que se hayan vuelto a dibujar cada una de las cartografías históricas tomadas como fuentes privilegiadas de la investigación, sino que estas mismas fueron utilizadas como documentos base para reconstruir la situación de la ciudad desde 1887 hasta 1945, con una periodización regular, en lapsos de diez años.

Para cada momento se utilizaron uno o más planos, debiéndose realizar, como exigencia metodológica, la compatibilización de los datos que cada uno contenía. Se conformó así un plano base para cada momento, que permitió luego, realizar planos temáticos determinados por los diversos indicadores de urbanización y su desarrollo en cada una de las etapas.

Los indicadores utilizados fueron diez en total: cuatro de ellos referidos a la estructura urbana en sus aspectos más estables (red vial y ferrovial, espacios verdes y equipamientos) y los seis restantes, referidos a las dinámicas de urbanización y ocupación de la ciudad (densidad de población, servicios públicos de energía eléctrica, agua corriente, cloacas, transporte público de tranvía y ómnibus). No fue posible construir todos los indicadores en cada período, dado que algunos de ellos fueron surgiendo de manera sucesiva y ya comenzado el siglo XX. No obstante, la construcción de estos planos temáticos ha hecho posible avanzar sobre los procesos urbanos de la ciudad, verificando y refutando hipótesis interpretativas previas. A su vez, la construcción de cada indicador hizo necesaria la consulta de múltiples fuentes y archivos que a veces, muy trabajosamente, permitieron que se obtuvieran los datos necesarios.

Todos los planos base fueron dibujados a la misma escala, con los mismos códigos de representación, utilizando un programa de diseño asistido que permitió la vectorización de la totalidad de la información y que asimismo generó archivos que posibilitan su utilización para posteriores elaboraciones y de ser necesario, para la actualización de los resultados.

Merece un párrafo especial la recopilación de ocho planes urbanos para la ciudad, dos parciales y seis generales. Estos son: el bulevar Gálvez y el barrio Candioti (1887), el proyecto de un bulevar de circunvalación para la ciudad (1887), el plan del intendente Juan Arzeno (1889), el plan del intendente Edmundo Rosas (1908), el plan del concejal Edmundo Escobar (1915), el Plan de Urbanización (1927), el plan de relleno de los Bajos del Salado (1928) y el Plan de Urbanización de Miguel Roca (1944).

Aunque la mayoría de ellos no fueron concretados por completo, su recopilación y sobre todo su reconstrucción sobre las respectivas plantas de la ciudad contemporáneas a cada uno, permite realizar varias operaciones que hasta el momento habían sido imposibles. Entre estas está la mejor comprensión de los mismos, dado que mucho de este material se ha elaborado compilando memorias, ordenanzas y noticias periodísticas, entre otros documentos puesto que no siempre se encontraban, o simplemente no existían, las publicaciones que le habían dado origen. Se pudo poner en evidencia su influencia sobre los proyectos urbanos y el diseño de la ciudad ya que si bien los planes no fueron con- 
cretados, orientaron más de una vez el desarrollo de la ciudad y permitieron hacer accesible este material tan disperso y diverso de manera sencilla y comprensible.

\section{Algunas conclusiones}

En lo que respecta a la cartografía, la construcción de un Atlas Histórico como el que aquí se presenta, que puede servir como instrumento analítico-comparativo, implicó dos líneas bien definidas de trabajo: por una parte, la lectura crítica de la cartografía histórica disponible para las distintas etapas y por otra, la construcción de una nueva cartografía que restituya la secuencia de crecimiento urbano en sucesivos cortes temporales para disponer de una base cartográfica homogénea, esencial para ejercitar la tarea de comparación, de la que se pueden derivar los planos temáticos referidos a los distintos indicadores del nivel de urbanización de la ciudad para cada momento histórico.

Los planos temáticos, al explicitar espacialmente los indicadores de urbanización para las distintas etapas de la vida de la ciudad, identificando usos del suelo, midiendo niveles de infraestructuras, de servicios, densidades de población y actividad, permitieron la lectura estructural de la ciudad en sus distintos momentos, superando la mera observación morfológica.

En la construcción del atlas, en la lectura crítica de los documentos de distinta índole que hemos referido, en la producción paralela de cartografías temáticas para los distintos cortes históricos establecidos, se asumió el desafío que implica comprender los procesos desde la perspectiva del estudio comparado, perspectiva novedosa en los estudios de historia urbana operados sobre ciudades argentinas.

A la vez, este método de reconstrucción cartográfica le agrega otro valor a la interpretación de la ciudad: le aporta contemporaneidad a la visualización de los procesos, restándoles, aunque sea parcialmente, la carga propia de los planos históricos y acercándolos a miradas más actuales que los relacionan con las coyunturas vigentes de la ciudad. Situados en el presente, fue posible identificar tanto problemas que se reiteran, como soluciones más o menos inéditas que se arriesgaron para intentar resolverlos.
Asimismo, al representar los indicadores de modernización se hizo posible, además de la comparación, la comprensión de cómo la infraestructura técnica fue avanzando paralelamente al proceso de modernización, pero no en una secuencia lineal, sino distanciándose o aproximándose al mismo en función de condicionantes políticos y económicos que fueron así identificados con mayor facilidad.

Se tiene conciencia de que al seleccionar y elegir el momento del registro, el método y el modo de operar, se estaba generando también una operación ideológica sobre el objeto en sí. $\mathrm{Al}$ digitalizar toda la información utilizando los más avanzados medios técnicos disponibles en materia de gráfica digital, se llegó a conformar una base de datos que ha permitido generar materiales multimediales de alto interés para el re-conocimiento de la ciudad actual.

Se entiende que el atlas constituye en sí mismo un objeto de cultura urbana, siendo este un modo de observar el objeto ciudad que permite una aproximación novedosa y enriquecedora de la cultura urbana de las ciudades argentinas.

\section{Referencias}

Berger, J. (2000). Modos de ver. Barcelona: Gustavo Gili.

Chartier, R. (1992). El mundo como representación, Barcelona: Gedisa.

Choay, F. (2007). Alegoría del Patrimonio. Barcelona: Gustavo Gili.

Corboz, A. (1994). La ciudad desbordada. En A. García Espuche. Ciudades: del globo al satélite (pp. 219-228). Madrid: Electa.

Corboz, A. (1995). Breve tipología de la imagen urbana. En A. García Espuche y T. Navas. Retrat de Barcelona (pp. 311-320). Barcelona: Edic. CCCB.

Da Costa, F. (2009).Atlas Histórico de Ciudades. Perspectivas Urbanas / Urban Perspectives, 10. Obtenido el 7 de noviembre de 2012. Recuperado de http://www.etsav.upc.es/ urbpersp/

Fanelli, G. (1985). Le città nella storia d'Italia: Firenze. Roma-Bari: Laterza.

Favelukes, G. (2011). Figuras y paradigmas. Las formas de Buenos Aires (1740-1870). En Anales del IAA (pp. 11-26). Buenos Aires: UBA. 
Graves, R. (2007). Mitos Griegos. Buenos Aires: Alianza.

Grimal, P. (1981). Diccionario de Mitología Griega y Romana. Buenos Aires: Paidós.

Guardia, M.; Monclús, F. J. y Oyón, J. L. (1997). Gli atlanti di città, fra descrizione e comparazione. Storia Urbana 81, 117-138.

Guidoni, E. (1979). Editoriale. En Storia della Cittá, 12/13, 3-4. Milano: Electa.

Monclús, F. J. (1989). Teorías arquitectónicas y discurso urbanístico. Ciudad y Territorio, 79, 25-40.

Nuti, L. (1996). Ritratti di città. Visione e memoria tra Medioevo e Settecento. Venezia: Marsilio.
Oyón, J. L. (1997). Recensión a Madrid. Atlas Histórico de la Ciudad. Historia Urbana, 4, 139.

Pabón de Urbina, J. (2005). Diccionario Manual Griego. Barcelona: Vox.

Piccinato, G. (1977). La costruzione dell'urbanistica. Roma: Officina Edizioni.

Saer, J. J. (1991). El río sin orillas. Tratado imaginario. Buenos Aires: Alianza.

Sica, P. (1981). Historia del urbanismo. El siglo XIX, vol. $2^{\circ}$, Madrid: IEAL.

Sontag, S. (2006). Sobre la fotografía. Buenos Aires: Alfaguara.

Warburg, A. (2010). Atlas Mnemosyne. Madrid: Akal.

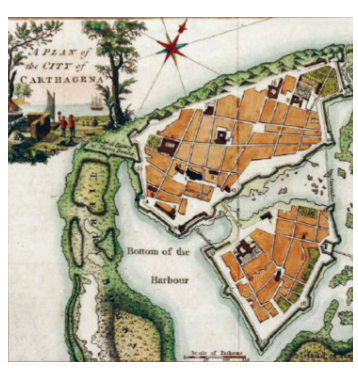

